\title{
Expression of major histocompatibility complex class I-related chain A/B (MICA/B) in pancreatic carcinoma
}

\author{
ZILVINAS DAMBRAUSKAS ${ }^{1}$, HELENA SVENSSON $^{2}$, MEGHNAD JOSHI $^{2,3}$, \\ ANDERS HYLTANDER ${ }^{2}$, PETER NAREDI $^{2}$ and BRITT-MARIE IRESJÖ ${ }^{2}$
}

\begin{abstract}
${ }^{1}$ Department of Surgery and Institute for Research of Digestive System, Lithuanian University of Health Sciences, Kaunas, Lithuania; ${ }^{2}$ Department of Surgery, Institute of Clinical Sciences, Sahlgrenska Academy, Sahlgrenska University Hospital, Gothenburg, Sweden; ${ }^{3}$ Stem Plus Biotech, Block \#11, Shiv Meridian, MG Road, Sangli 416416, MS, India
\end{abstract}

Received July 21, 2013; Accepted September 9, 2013

DOI: 10.3892/ijo.2013.2156

\begin{abstract}
Major histocompatibility complex class I-related chain A and B (MICA/B) are two stress-inducible ligands that bind to the immunoreceptor NKG2D and play an important role in mediating cytotoxicity of NK and T cells. Release of MIC molecules from the cell surface is thought to constitute an immune escape mechanism of tumor cells and thus could be associated with more aggressive course of tumor growth. In this study, we investigated the expression of MICA/B in ductal pancreatic carcinoma and serum in relation to tumor stage, differentiation and survival. MICA/B expression in tumor tissues and sera from patients with pancreatic cancer were analyzed by immunohistochemical staining (IHC), western blotting and ELISA, respectively. MICA/B expression was present in 17 of $22(77 \%)$ of the tumors but not in normal pancreatic ductal epithelial cells. Poorly differentiated tumors showed more pronounced MICA/B expression compared to differentiated tumors, but did not correlate significantly to other tumor characteristics. MICA/B-negative tumors displayed significantly lower incidence of lymph node metastases $(\mathrm{p}<0.01)$, and less mortality within 3 years following resection $(\mathrm{p}<0.02)$. In conclusion, tissue levels of MICA/B expression were elevated in pancreatic cancer cells without elevated levels in serum, despite well-recognized acute phase reactants in serum. Poorly differentiated tumors showed high MICA/B expression, which was related to extended tumor lymph node metastases and less frequent long-term survival.
\end{abstract}

\section{Introduction}

Pancreatic cancer is a disease with poor prognosis and still overall 5 -year survival rate of $<20 \%$ (1) without any

Correspondence to: Dr Britt-Marie Iresjö, Department of Surgery, Sahlgrenska University Hospital, Kir. Metabol laboratory, Bruna Stråket 20, S-413 45 Gothenburg, Sweden

E-mail: britt-marie.iresjo@surgery.gu.se

Key words: pancreatic cancer, MICA/B, cancer differentiation substantial treatment improvement during the past 30 years. This is in contrast to many other tumor diseases where earlier diagnosis and significant adjuvant treatment usually improved survival (2-4). Pancreatic carcinomas are virtually resistant to radiotherapy as well as chemotherapy, and surgery remains the only option for cure $(1,5,6)$. Therefore, alternative treatment strategies are highly needed and immunomodulatory methods among others are in focus. However, to optimize immunotherapy of pancreatic carcinoma a further understanding of mechanisms behind tumor-host interactions are required (7-9).

MICA is a glycosylated, polymorphic and membrane anchored non-classical MHC class I molecule. It is a stress induced protein normally expressed in intestinal epithelial cells only, but found to be broadly expressed in a variety of malignant tumors as melanoma, breast, colon and hepatocellular cancers (10-12). It functions as a ligand for the NKG2D receptor, which is an important immunoreceptor on NK cells, CD 8 and $\gamma \delta$ T-cells. The molecule can be cleaved by matrix metalloproteinases and ADAM proteinase, and may then be released into the blood stream or tissue culture medium as a soluble molecule (sMICA) (13-15). Accordingly, it has been suggested that high levels of sMIC in serum from patients with certain gastrointestinal malignancies can cause systemic downregulation of NKG2D surface expression on CD8 $\alpha \beta$ $\mathrm{T}$ cells and NK cells, which may impair lysis of tumor cells $(11,16)$. Therefore, our present aim was to analyze MICA/B expression in pancreatic tumor tissue and serum associated to tumor stage.

\section{Materials and methods}

Patient material, tumor specimens and blood samples. The use of specimens from human subjects was approved by the Institutional Review Board of Lithuanian University of Medical Sciences (Kaunas, Lithuania) and the regional ethics board in Gothenburg (Sweden). Pancreatic cancer tissue samples used in IHC and western blot analyses were derived from the surgical specimens removed from 22 patients undergoing pancreatoduodenal resections for pancreatic cancer at Department of Surgery at the Hospital of Lithuanian University of Medical Sciences (Kaunas, Lithuania). Six specimens of normal pancreas tissues were collected from liver and/ 
or kidney organ donors. All tissue samples were snap-frozen in liquid nitrogen and stored at $-80^{\circ} \mathrm{C}$ until analysis. Paraffinembedded tissue blocks from the same patients were obtained from the Department of Pathology and used to assess tumor differentiation and stage of the pancreatic adenocarcinomas according to TNM classification by certified independent pathologists. Blood samples were collected from 13 individuals with pancreatic ductal adenocarcinoma undergoing surgery at Sahlgrenska University Hospital (Gothenburg, Sweden). Pancreatic cancer tissue as well as non-tumor pancreatic tissue from the same patients were also collected. Tissues were put in RNAlater solution and stored at $-20^{\circ} \mathrm{C}$ until analysis. Tissue samples from 4 of the 13 patients were used in the Western blot analysis. Serum from 10 healthy blood donors was collected as controls (although such individuals are younger than the average cancer-patients they are systematically screened for abnormalities). Serum samples were centrifuged, aliquoted, and stored at $-80^{\circ} \mathrm{C}$ until analysis of sMICA using a sandwich ELISA as described below. Patient characteristics are given in Table I.

Immunohistochemical (IHC) analysis. Frozen pancreatic tissue sections $(5-7-\mu \mathrm{m})$ were air-dried and fixed in a mixture of ice-cold acetone and $10 \%$ formaldehyde for $5 \mathrm{~min}$ at $-20^{\circ} \mathrm{C}$. Tissue sections were stained with an anti-MICA/B (H-300) rabbit polyclonal antibodies in 1:200 dilution (Santa Cruz Biotechnology, Inc., Santa Cruz, CA, USA) as previously described (17). Rabbit IgG in an equivalent concentration was used as a negative control employing a similar immunohistochemical staining procedure. Two investigators graded MICA/B expression in a blinded fashion. Negative MICA/B expression was graded as no MICA/B signal (-). MICA/Bpositive tumors were defined as having weak $(+)$, moderate $(++)$ or strong (+++) MICA/B signal.

Western blot analysis. Freshly frozen or RNAlater treated pancreatic tumor tissue was homogenized with a rotor-stator homogenizer to five times the tissue weight of RIPA buffer (50 mM Tris- $\mathrm{HCl}$ at $\mathrm{pH} 8.0,0.1 \%$ sodium dodecyl sulfate, $1 \%$ Nonidet P-40, $150 \mathrm{mM} \mathrm{NaCl}$ and $0.5 \%$ deoxycholic acid) with complete protease inhibitors added (Roche Diagnostics Gmbh, Germany). Homogenates were then centrifuged at $10,000 \mathrm{~g}$ for $10 \mathrm{~min}$. Protein concentrations were determined with Bradford Coomassie assay (Bio-Rad Laboratories Inc., Hercules, CA, USA). Next $30 \mu \mathrm{g}$ total protein of each sample was separated by electrophoresis in $4-12 \%$ Bis-Tris sodium dodecyl sulfate-polyacrylamide gels (Invitrogen, Carlsbad, CA, USA) at $200 \mathrm{~V}$ for $50 \mathrm{~min}$ and transferred to $0.2 \mu \mathrm{M}$ PVDF membranes (Bio-Rad Laboratories). After blocking in $10 \%$ non-fat dry milk, membranes were incubated overnight at $4^{\circ} \mathrm{C}$ with a rabbit polyclonal anti-MICA/B (sc-20931, Santa Cruz Biotechnology) 1:600 dilution in 3\% dry milk. Membranes were incubated for $1 \mathrm{~h}$ at room temperature with peroxidase labeled anti-rabbit IgG as secondary antibody (GE Healthcare). Immunocomplexes were visualized using the Amersham Hyperfilm ECL Western blotting analysis system (GE Healthcare). The film was scanned in a GS-710 calibrated densitometer (Bio-Rad Laboratories) and quantified using Quantity One software. The optical density was measured and expressed in arbitrary units. Two lanes on each gel were
Table I. Patient characteristics (mean \pm SE).

\begin{tabular}{lccc}
\hline $\begin{array}{l}\text { General } \\
\text { characteristics }\end{array}$ & Tumor patients & Tumor patients & Blood donors
\end{tabular}

\begin{tabular}{lccc}
\hline Gender & & & \\
Female & 14 & 9 & 2 \\
Male & 8 & 4 & 8 \\
Age (years) & $66 \pm 2$ & $67 \pm 2$ & $40 \pm 4$ \\
S-CRP (mg/l) & $24 \pm 6$ & $16 \pm 8$ & $<5$
\end{tabular}

S-CRP, C-reactive protein (serum).

loaded with Magic Mark XP protein standard (Invitrogen Inc.). The average density of a standard band was used to normalize signal intensity between the blots.

Protein digestion and identification by $L C$-MS/MS. Proteins were electrophoretically separated as described for western blots and thereafter Coomassie stained. The protein gel band was excised, washed and dried prior to digestion with trypsin $\left(50 \mathrm{mM} \mathrm{NH} \mathrm{HCO}_{3}, 10 \mathrm{ng} / \mu \mathrm{l}\right.$ trypsin) at $37^{\circ} \mathrm{C}$ overnight. Peptides were extracted, dried and reconstituted in $0.2 \% \mathrm{HCOOH}$. The sample was analyzed with nanoflow LC-MS/MS using a column packed in-house with $3 \mu \mathrm{m}$ Reprosil-Pur $\mathrm{C}_{18}$-AQ particles connected to an LTQ-Orbitrap $\mathrm{XL}$. An acetonitrile gradient in $0.2 \% \mathrm{HCOOH}$ was used for separation of the peptides.

The LTQ-Orbitrap was operated in a data-dependent mode, switching between one MS1 FTMS scan precursor ions scan followed by CID (collision induced dissociation) fragmentation (MS/MS) of the six most intense, protonated ions in each FTMS scan. All the tandem mass spectra were searched by MASCOT (Matrix Science, London) against the Uniref100 protein database. The search parameters were set to: human, MS accuracy $5 \mathrm{ppm}, \mathrm{MS} / \mathrm{MS}$ accuracy $0.5 \mathrm{Da}$, one missed cleavage by trypsin allowed and variable modification of propionamide modification of cysteine and oxidized methionine.

ELISA analysis. MICA concentrations in serum from pancreatic cancer patients and from healthy blood donors (13 and 10 individuals, respectively) were determined by using DuoSet ELISA (R\&D systems Abington, UK) according to the manufacturer's instructions.

Quantification of serum proteins. Quantification of CRP and serum protein electrophoresis were performed as routine analyses at the Laboratory for Clinical Chemistry at Sahlgrenska University Hospital.

Statistical analysis. Results are reported as the mean \pm SEM. Chi-square tests were performed to analyze the difference in the clinicopathological parameters of MICA/B positive and MICA/B-negative pancreatic ductal adenocarcinomas for significant association. Factorial ANOVA followed by Fisher's PLSD post hoc test was used to analyze differences 
A

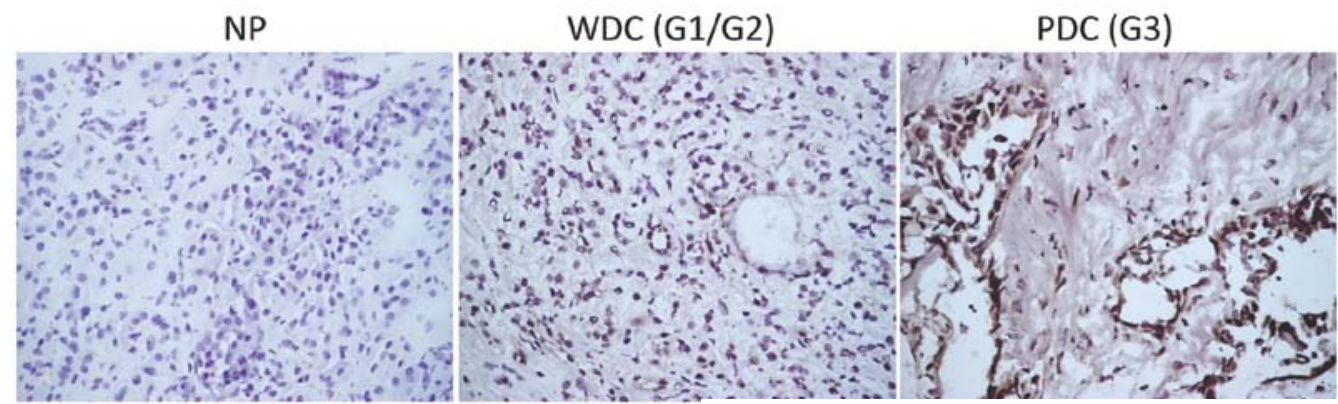

B

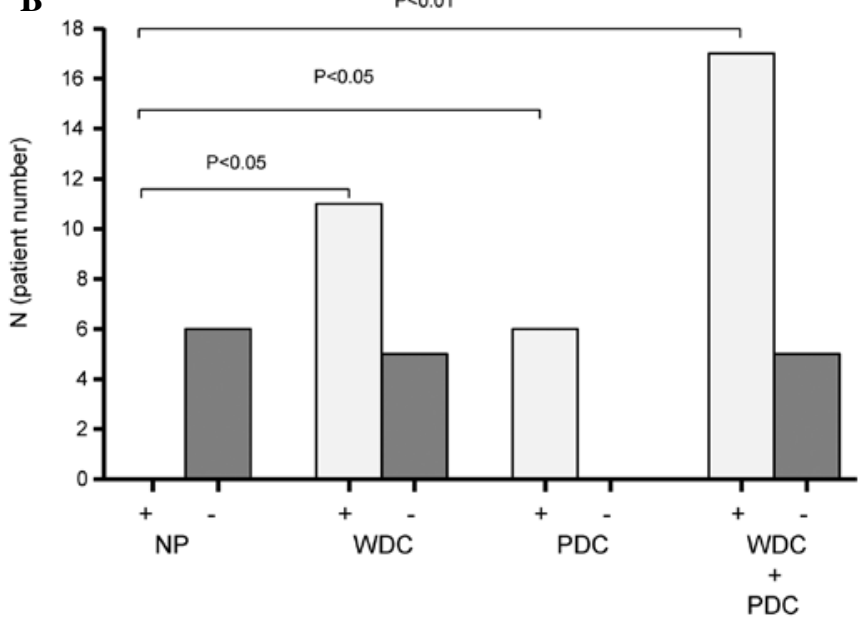

Figure 1. Immunohistochemical staining of MICA/B expression in pancreatic tumor tissue according to differentiation grade. Representative images of MICA/B expression in normal pancreatic (NP), well differentiated (WDC) and poorly differentiated (PDC) pancreatic tumor tissue are shown in (A) MICA/B expression was determined by immunohistochemical staining using DAB, and counterstaining with hematoxylin. (B) Illustrates the numbers of MICA/B positive and negative tumor compared to normal pancreas tissue (NP, n=6), as observed in well differentiated tumor tissue (WDC, $\mathrm{n}=16$ ) and poorly differentiated tumor tissue (PDC, $\mathrm{n}=6$ ) as well as observed in all tumors (WDC+PDC, $\mathrm{n}=22$ ).

among groups in MIC A/B western blotting protein expression. Mann-Whitney U test was used to compare serum MICA levels between pancreatic cancer patients and controls. A $\mathrm{p}<0.05$ was considered statistically significant in two-tailed tests. All statistics were conducted by using SPSS 11.5.

\section{Results}

Tissue expression of $M I C A / B$ in pancreatic tumors. Pancreatic cancer specimens from 22 patients with primary adenocarcinomas ( 8 male and 14 female) with a mean age of $66 \pm 8$ years (range 50-79 years) and six samples of normal pancreas from liver and/or kidney donors (4 male and 2 female) were analyzed for MICA/B expression by immunohistochemical staining (IHC) according to the above described protocols. The mean survival time of the cancer patients after surgery was 479 \pm 275 days (range 124-1,210 days).

IHC staining with rabbit polyclonal anti-MICA/B revealed a strong specific dark brown signal of MICA/B expression present in $17(77 \%)$ of 22 pancreatic adenocarcinomas. Specific staining was only observed in tumor cells but not in normal pancreatic tissue cells (Fig. 1A). The negative control by rabbit IgG did not show any signal. Negative pancreatic adenocarcinomas were defined according to a lack of specific staining in tumor cells. More than half $(69 \%)$ of the well differentiated tumor specimens (G1-G2) and all (100\%) of the poorly differentiated tumor specimens (G3) showed positive staining for MICA/B (Fig. 1).

Clinicopathological analyses indicated that expression of MICA/B was not related to patient gender, age or post-operative survival, tumor size, tumor differentiation or perineural invasion. However, statistical analysis confirmed that MICA/ B-negative tumors $(23 \%)$ were associated with significantly lower mortality during postoperative follow-up $(\mathrm{p}=0.021)$, and lower incidence of regional lymph node metastases $(p=0.003$; Table II).

Western blot analysis was performed on RIPA extracted homogenized pancreatic tissue in order to quantify tissue levels of MICA/B in normal (donor), non-tumor and tumor pancreatic tissue. The MICA/B antibody showed three bands with strong immunoreactivity. Optical density was analyzed for the band at $\sim 38$ kDA. A representative blot is shown in Fig. 2A. Visual inspection indicated that expression of MICA/B in the $38-\mathrm{kDa}$ band was lower in normal pancreas tissue compared to tumor tissue (Fig. 2A). It was evident that protein levels of MICA/B were significantly higher in both poorly and well differentiated pancreatic tumor tissue when compared to nontumor pancreatic tissue ( $\mathrm{p}<0.001$ for both; Fig. 2B). Poorly differentiated tumors (G3) had higher MICA/B expression than well differentiated tumors $(\mathrm{G} 1-\mathrm{G} 2 ; \mathrm{p}<0.05)$. No difference was found in MICA/B expression from normal pancreas from organ donors compared to 'next-to-cancer' non-tumor pancreatic tissue (pancreatic tissue obtained from resected specimens of cancer patients but containing no tumor).

The 38-kDa band of a Coomassie stained gel was subjected to masspectrometric analysis to verify the specificity of the MICA/B antibody since immune based analyses may be hampered by unspecific binding of antibodies. Protein fragments in the gel-band could be matched to the MICA/B protein sequence which supports that the immunoreactive 38-kDa band represents MCA/B (data not shown).

Serum proteins and SMICA in pancreatic cancer patients and healthy blood donors. Electrophoretic separation of serum proteins was performed to check the extent pancreatic cancer patients were systemically affected by their disease. Serum proteins showed decreased levels of $\operatorname{IgM}(0.54 \pm 0.06$ vs $1.04 \pm 0.16 \mathrm{~g} / \mathrm{l}), \operatorname{IgG}(6.6 \pm 0.6$ vs $10.8 \pm 0.5 \mathrm{~g} / \mathrm{l})$ and albumin $(25 \pm 1$ vs. $45 \pm 1 \mathrm{~g} / \mathrm{l})$; increased levels of haptoglobin $(1.1 \pm 0.1$ vs $0.7 \pm 0.1 \mathrm{~g} / \mathrm{l})$ without a difference in orosomucoid $(0.7 \pm 0.1$ vs $0.8 \pm 0.1 \mathrm{~g} / \mathrm{l})$ or $\alpha 1$-antitrypsin levels $(1.2 \pm 0.1$ vs $1.3 \pm 0.1 \mathrm{~g} / \mathrm{l})$ 
Table II. MICA/B expression in pancreatic cancer and clinicopathological significance (mean \pm SE).

\begin{tabular}{|c|c|c|c|c|}
\hline $\begin{array}{l}\text { Clinical } \\
\text { characteristics }\end{array}$ & $\mathrm{MICA} / \mathrm{B}^{+}$ & $\mathrm{MICA} / \mathrm{B}^{-}$ & Total & p-value \\
\hline \multicolumn{5}{|l|}{ Gender } \\
\hline Female & 11 & 3 & 14 & 0.620 \\
\hline Male & 6 & 2 & 8 & \\
\hline Age (years) & $64 \pm 2$ & $71 \pm 3$ & $66 \pm 2$ & 0.120 \\
\hline \multicolumn{5}{|l|}{ Tumor size } \\
\hline $\mathrm{T} 3$ & 16 & 4 & 20 & 0.441 \\
\hline $\mathrm{T} 4$ & 1 & 1 & 2 & \\
\hline \multicolumn{5}{|l|}{$\begin{array}{l}\text { Regional lymph } \\
\text { nodes }\end{array}$} \\
\hline No & 1 & 4 & 5 & 0.003 \\
\hline N1 & 16 & 1 & 17 & \\
\hline \multicolumn{5}{|l|}{$\begin{array}{l}\text { Distant } \\
\text { metastases }\end{array}$} \\
\hline M0 & 17 & 5 & 22 & NS \\
\hline M1 & 0 & 0 & 0 & \\
\hline \multicolumn{5}{|l|}{ Tumor } \\
\hline G1-G2 & 10 & 5 & 15 & 0.114 \\
\hline G3 & 7 & 0 & 7 & \\
\hline \multicolumn{5}{|l|}{$\begin{array}{l}\text { Perineural } \\
\text { infiltration }\end{array}$} \\
\hline Yes & 9 & 4 & 13 & 0.293 \\
\hline No & 8 & 1 & 9 & \\
\hline \multicolumn{5}{|l|}{$\begin{array}{l}\text { Death during } \\
\text { follow-up }\end{array}$} \\
\hline Yes & 14 & 1 & 15 & 0.021 \\
\hline No & 3 & 4 & 7 & \\
\hline Survival (days) & $461 \pm 65$ & $542 \pm 146$ & $479 \pm 59$ & 0.704 \\
\hline
\end{tabular}

NS, No statistics calculated. Bold, statistically significant.

in pancreatic cancer patients compared to blood donors. CRP levels were increased in $70 \%$ of the patient samples (mean $16 \pm 8 \mathrm{mg} / \mathrm{l}$; normal values $<5 \mathrm{mg} / \mathrm{l}$ ). Concentrations of sMICA in serum from the cancer patients were normal, despite the well-recognized alterations in serum acute phase proteins. The mean serum concentration of sMICA in blood donors was $50 \pm 14$ and $40 \pm 13 \mathrm{pg} / \mathrm{ml}$ in cancer patients. Thus, there was no inference between serum MICA and tumor stage.

\section{Discussion}

It has been reported that expression of MICA/B is increased in several types of malignancies (10), although studies examining MICA/B expression in pancreatic cancer are few, particularly

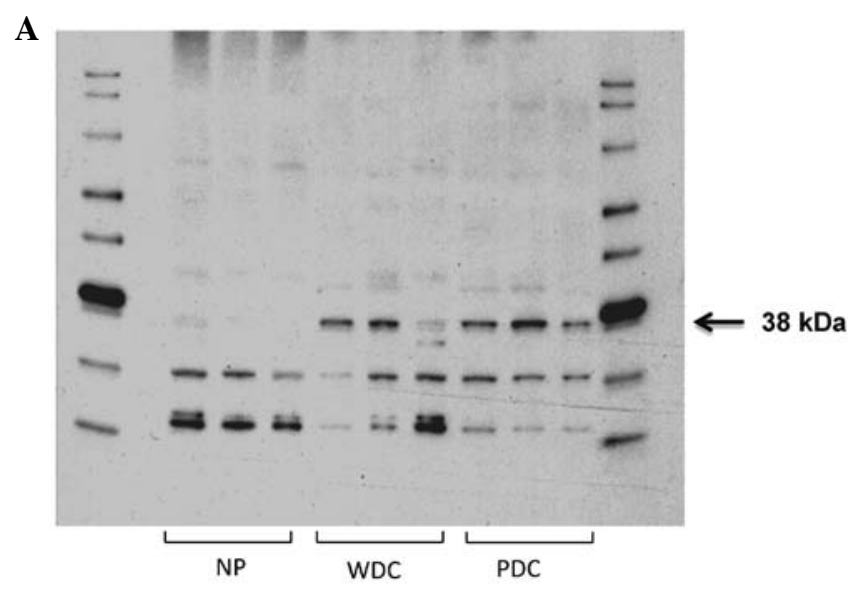

B

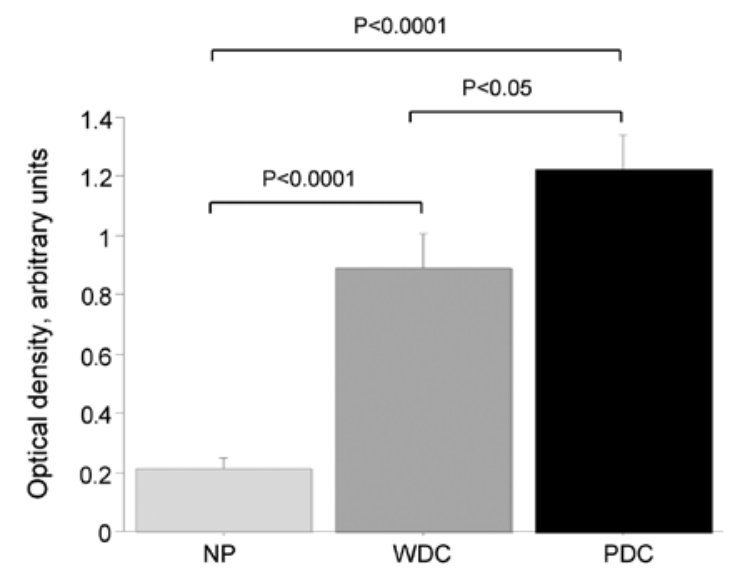

Figure 2. Western blot analysis of MICA/B content in pancreatic tumor tissue related to differentiation grade. A representative blot of MICA/B expression in RIPA-extracted proteins from pancreatic tissue is shown (A). Samples were from normal tissue (NP, lanes 3-5), well differentiated pancreatic tumor tissue (WDC, lanes 5-7) and poorly differentiated pancreatic tumor tissue (PDC, lanes 9-11). Standard proteins are applied in lanes 1 and 12. The optical density of the $38 \mathrm{kDa}$ band was measured and expressed in arbitrary units. Mean \pm SEM was calculated for each group (B). A statistical comparison of the optical density among the groups showed that MICA/B expression in PDC was significantly higher than in WDC $(\mathrm{p}<0.05)$. MICA/B expression was significantly increased in both tumor groups compared to normal pancreatic tissue $(\mathrm{p}<0.001)$. Normal pancreas tissue $(n=6)$ as well as non-tumor pancreas $(n=4)$ are included in the NP group, (total $n=10)$, (WDC, $\mathrm{n}=13)$ and $(\mathrm{PDC}, \mathrm{n}=7)$.

in patients from European countries. In the present study we focused on MICA/B expression in pancreatic tumor tissue and found that in 17 of 22 (77\%) of the tumor specimens MICA/B were detected by immunohistochemistry, while it was entirely absent in normal pancreatic duct epithelial cells. This agrees with the study of Xu et al, performed on North Americans who found MICA/B expressed in 17 of 25 (68\%) tumor specimens (18). In addition to this, a large Chinese study performed by Duan et al on 103 pancreatic ductal adenocarcinomas reported that MICA/B expression was observed in 92 of 103 patients (89\%) (19).

Tissue distributions of MICA in normal tissue is restricted to intestinal epithelial cells (20), but the protein may be upregulated in various types of tumor cells of epithelial origin as well as in tumor cell lines, possibly due to physical stress $(10,21)$. MICA functions as a ligand for the NKG2D receptor and may promote signals for lysis, by both $\mathrm{NK}$ cells and $\mathrm{CD} 8^{+} \mathrm{T}$ cells. 
In vitro studies have provided strong evidence that MICA is important for the susceptibility of target T cells to NK cells, CD8 cytotoxic T cells, and $\gamma \delta \mathrm{T}$ cells. Tumor cells that stably express NKG2D ligands at high level may be rejected by CD8 $\mathrm{T}$ cells and/or NK cells and mice immunized with NKG2/D ligand-transfected tumor cells were reported to develop adaptive immunity against re-challenge with the parental tumor cell lines $(22,23)$. Accordingly, blocked interactions between MICA and NKG2D with antibodies inhibit NK and T cellmediated cytolysis (24). It seems, however, rather contradictory that pancreatic tumors, associated with poor prognosis, should induce expression of MIC, which is assumed to make tumor cells more susceptible to immune attack and apoptosis.

Studies on MICA/B expression in tumors demonstrate somewhat conflicting results. Increased expression of tumor MICA/B has been shown to correlate with both increased survival and improved prognosis in colorectal carcinomas (25), while others have found opposite results in pancreatic cancers (19). In the present study there was no significant difference in post-operative survival time between patients with MICA/B positive and negative tumors, but such calculations must be based on large number of patients, but significantly higher 3-year mortality in patients with MICA/B-positive tumors was found. Such discrepancies might be explained by the fact that MICA/B tumor expression was associated with regional lymph node involvement, since tumor spread to regional lymph nodes was significantly less frequent among patients with MIC-negative tumors.

It has been suggested that MICA/B expression is associated with poor prognosis, because MICA/B can be released from the tumor cells by proteolytic shedding, perhaps with final appearance of its soluble form in blood. This would help tumors to escape immune surveillance, since the release of sMICA/B and other NKG2D ligands has the ability to inhibit interaction of NK cells with the activating receptor, thereby, protecting the ligand expressing tumor cells from cytolysis $(19,26)$. However, our present study showed normal levels of sMICA in serum from pancreatic cancer patients, confirmed by comparisons to healthy blood donors. Others have reported significantly elevated levels of MICA in serum from patients with pancreatic adenocarcinomas, without any correlation to tumor stage and survival (18). However, Duan et al reported that mean survival time of pancreatic cancer patients, with low serum levels of MICA, was significantly longer than the mean survival time of patients with high levels (19). Some studies have reported that elevated sMICA correlated significantly to tumor stage in pancreatic cancer patients and that sMICA levels dropped in serum from patients following tumor resection $(26,27)$. However, sMIC levels in serum have been argued not to be specific enough as an individual prognostic tumor marker (26), although, a recent study claimed that both sMICA and SMICB are potential biomarkers for pancreatic ductal adenocarcinoma, and that serum levels of sMICA correlated with distant metastases and SMICB with unresectability (28). So far, there is no obvious reason for described inconsistence in observations among reported studies on sMICA. However, the definite relationships between MICA and pancreatic tumor progression must await further technical considerations, since we have observed variation between specificity and serum components among patient samples analyzed by the commer- cially available analysis kits. This may introduce particular hazards for samples with increased acute phase proteins, as often found to various extent in cancer patients. Another factor may be the fact that the highly glycosylated MIC molecule is among the most polymorphic mammalian MHC genes known (29). MICA is highly polymorphic in transcellular and extracellular domains, resulting in several different MICA variants more or less common among different populations $(30,31)$. Thus, different antibodies used in the ELISA might detect different forms of diverse MICA/B proteins since reported levels of MICA showed large variations even in healthy individuals $(18,32)$. Recent studies in cultured cells imply that MICA/B shedding is far more complex than initially thought $(33,34)$. Chitadze et al showed that shedding of MICA varied substantially among different epithelial cancer cell lines. Furthermore, they failed to detect sMICA from cells expressing the allelic variant MICA*008; the most common allelic variant in Caucasian populations (35).

Molecular mechanisms for increased expression of MICA/B in tumor cells are not known, but studies indicate that MAP kinase activation through BRAF gene mutation as well as STAT 3 transcriptional regulation may be involved $(17,36)$. Observations have also supported suggestions that uric acid accumulation in DNA-damaged pancreatic cancer cells play an important role for induction of MICA/B expression (18).

In conclusion, the present study confirms induced expression of MICA/B protein in pancreatic tumor cells, but without subsequent net appearance of MICA in serum despite the presence of well-recognized systemic inflammation in our pancreatic cancer patients as demonstrated by serum acute phase reactants. The expression in pancreatic cancer cells increased with loss of tumor differentiation and further disease progression. Our study implies that induction of MICAB tumor expression was associated with frequent tumor spread to the regional lymph nodes leading to increased 3-year mortality following surgical resection.

\section{Acknowledgements}

This study was supported in parts by grants from the Swedish Cancer Society, Assar Gabrielsson Foundation (AB Volvo) and the Swedish government (LUA-ALF). We would like to thank The Proteomics Core Facility at Sahlgrenska Academy, Gothenburg University for performing the mass spectrometry analysis. The purchase of LTQ-OrbitrapXL was made possible through a grant from the Knut and Alice Wallenberg Foundation to Professor Gunnar C. Hansson (KAW2007.0118). We acknowledge Professor Kent Lundholm for support of this study.

\section{References}

1. Wagner M, Redaelli C, Lietz M, Seiler CA, Friess H and Buchler MW: Curative resection is the single most important factor determining outcome in patients with pancreatic adenocarcinoma. Br J Surg 91: 586-594, 2004.

2. Bramhall SR, Allum WH, Jones AG, Allwood A, Cummins C and Neoptolemos JP: Treatment and survival in 13,560 patients with pancreatic cancer, and incidence of the disease, in the West Midlands: an epidemiological study. Br J Surg 82: 111-115, 1995.

3. Jemal A, Siegel R, Ward E, et al: Cancer statistics, 2008. CA Cancer J Clin 58: 71-96, 2008. 
4. McCracken M, Olsen M, Chen MS Jr, et al: Cancer incidence, mortality, and associated risk factors among Asian Americans of Chinese, Filipino, Vietnamese, Korean, and Japanese ethnicities. CA Cancer J Clin 57: 190-205, 2007.

5. Buchler MW, Wagner M, Schmied BM, Uhl W, Friess $H$ and Z'Graggen K: Changes in morbidity after pancreatic resection: toward the end of completion pancreatectomy. Arch Surg 138: 1310-1315, 2003.

6. Diener MK, Heukaufer C, Schwarzer G, et al: Pancreaticoduodenectomy (classic Whipple) versus pylorus-preserving pancreaticoduodenectomy (pp Whipple) for surgical treatment of periampullary and pancreatic carcinoma. Cochrane Database Syst Re 16: CD006053, 2008.

7. Jaffee EM, Hruban RH, Biedrzycki B, et al: Novel allogeneic granulocyte-macrophage colony-stimulating factor-secreting tumor vaccine for pancreatic cancer: a phase I trial of safety and immune activation. J Clin Oncol 19: 145-156, 2001.

8. Picozzi VJ, Kozarek RA and Traverso LW: Interferon-based adjuvant chemoradiation therapy after pancreaticoduodenectomy for pancreatic adenocarcinoma. Am J Surg 185: 476-480, 2003.

9. Dranoff G: Coordinated tumor immunity. J Clin Invest 111: 1116-1118, 2003.

10. Groh V, Rhinehart R, Secrist H, Bauer S, Grabstein KH and Spies T: Broad tumor-associated expression and recognition by tumor-derived gamma delta T cells of MICA and MICB. Proc Natl Acad Sci USA 96: 6879-6884, 1999.

11. Groh V, Wu J, Yee C and Spies T: Tumour-derived soluble MIC ligands impair expression of NKG2D and T-cell activation. Nature 419: 734-738, 2002

12. Pende D, Rivera P, Marcenaro S, et al: Major histocompatibility complex class I-related chain A and UL16-binding protein expression on tumor cell lines of different histotypes: analysis of tumor susceptibility to NKG2D-dependent natural killer cell cytotoxicity. Cancer Res 62: 6178-6186, 2002.

13. Liu G, Atteridge CL, Wang X, Lundgren AD and Wu JD: The membrane type matrix metalloproteinase MMP14 mediates constitutive shedding of MHC class I chain-related molecule A independent of A disintegrin and metalloproteinases. J Immunol 184: 3346-3350, 2010.

14. Salih HR, Rammensee HG and Steinle A: Cutting edge: downregulation of MICA on human tumors by proteolytic shedding. J Immunol 169: 4098-4102, 2002.

15. Waldhauer I, Goehlsdorf D, Gieseke F, et al: Tumor-associated MICA is shed by ADAM proteases. Cancer Res 68: 6368-6376, 2008.

16. Doubrovina ES, Doubrovin MM, Vider E, et al: Evasion from NK cell immunity by MHC class I chain-related molecules expressing colon adenocarcinoma. J Immunol 171: 6891-6899, 2003.

17. Xu X, Rao G, Gaffud MJ, et al: Clinicopathological significance of major histocompatibility complex class I-related chain a and B expression in thyroid cancer. J Clin Endocrinol Metab 91: $2704-2712,2006$.

18. Xu X, Rao GS, Groh V, et al: Major histocompatibility complex class I-related chain A/B (MICA/B) expression in tumor tissue and serum of pancreatic cancer: role of uric acid accumulation in gemcitabine-induced MICA/B expression. BMC Cancer 11: 194 2011.

19. Duan X, Deng L, Chen X, et al: Clinical significance of the immunostimulatory MHC class I chain-related molecule A and NKG2D receptor on NK cells in pancreatic cancer. Med Oncol 28: 466-474, 2011
20. Groh V, Bahram S, Bauer S, Herman A, Beauchamp M and Spies T: Cell stress-regulated human major histocompatibility complex class I gene expressed in gastrointestinal epithelium. Proc Natl Acad Sci USA 93: 12445-12450, 1996.

21. Bauer S, Groh V, Wu J, et al: Activation of NK cells and T cells by NKG2D, a receptor for stress-inducible MICA. Science 285: 727-729, 1999.

22. Diefenbach A, Jensen ER, Jamieson AM and Raulet DH: Rae and H60 ligands of the NKG2D receptor stimulate tumour immunity. Nature 413: 165-171, 2001.

23. Hayakawa Y, Kelly JM, Westwood JA, et al: Cutting edge: tumor rejection mediated by NKG2D receptor-ligand interaction is dependent upon perforin. J Immunol 169: 5377-5381, 2002.

24. Raulet DH: Roles of the NKG2D immunoreceptor and its ligands. Nat Rev Immunol 3: 781-790, 2003.

25. Watson NF, Spendlove I, Madjd Z, et al: Expression of the stressrelated MHC class I chain-related protein MICA is an indicator of good prognosis in colorectal cancer patients. Int J Cancer 118: $1445-1452,2006$

26. Marten A, von Lilienfeld-Toal M, Buchler MW and Schmidt J. Soluble MIC is elevated in the serum of patients with pancreatic carcinoma diminishing gammadelta $\mathrm{T}$ cell cytotoxicity. Int $\mathrm{J}$ Cancer 119: 2359-2365, 2006.

27. Holdenrieder S, Stieber P, Peterfi A, Nagel D, Steinle A and Salih HR: Soluble MICA in malignant diseases. Int J Cancer 118: 684-687, 2006.

28. Chung HW and Lim JB: Clinical significance of serum levels of immune-associated molecules, uric acid and soluble MHC class I chain-related molecules A and B, as diagnostic tumor markers for pancreatic ductal adenocarcinoma. Cancer Sci 102: 1673-1679, 2011.

29. Bahram S: MIC genes: from genetics to biology. Adv Immunol 76: $1-60,2000$

30. Collins RW, Stephens HA, Clare MA and Vaughan RW: High resolution molecular phototyping of MICA and MICB alleles using sequence specific primers. Hum Immunol 63: 783-794, 2002.

31. Stephens HA: MICA and MICB genes: can the enigma of their polymorphism be resolved? Trends Immunol 22: 378-385, 2001

32. Arreygue-Garcia NA, Daneri-Navarro A, del Toro-Arreola A, et al: Augmented serum level of major histocompatibility complex class I-related chain A (MICA) protein and reduced NKG2D expression on NK and T cells in patients with cervical cancer and precursor lesions. BMC Cancer 8: 16, 2008.

33. Chitadze G, Lettau M, Bhat J, et al: Shedding of endogenous MHC class I-related chain molecules A and B from different human tumor entities: heterogeneous involvement of the 'a disintegrin and metalloproteases' 10 and 17. Int J Cancer 133: 1557-1566, 2013.

34. Ashiru O, Boutet P, Fernandez-Messina L, et al: Natural killer cell cytotoxicity is suppressed by exposure to the human NKG2D ligand MICA*008 that is shed by tumor cells in exosomes. Cancer Res 70: 481-489, 2010

35. Collins RW: Human MHC class I chain related (MIC) genes: their biological function and relevance to disease and transplantation. Eur J Immunogenet 31: 105-114, 2004.

36. Bedel R, Thiery-Vuillemin A, Grandclement C, et al: Novel role for STAT3 in transcriptional regulation of NK immune cell targeting receptor MICA on cancer cells. Cancer Res 71: 1615-1626, 2011. 